\title{
Differential expression of B-type natriuretic peptide between left and right ventricles, with particular regard to sudden cardiac death
}

\author{
ZHI-PENG CAO, JIA-JIA XUE, YUAN ZHANG, MEI-HUI TIAN, YING XIAO, YU-QING JIA and BAO-LI ZHU
}

\author{
Department of Forensic Pathology, School of Forensic Medicine of \\ China Medical University, Shenyang, Liaoning 110122, P.R. China
}

Received November 9, 2016; Accepted July 14, 2017

DOI: $10.3892 / \mathrm{mmr} .2017 .7136$

\begin{abstract}
The aim of the present study was to investigate the differential expression of B-type natriuretic peptide (BNP) between the left and right ventricle (RV) in sudden cardiac death (SCD). A total of 26 forensic autopsy cases of sudden death (survival time $<30 \mathrm{~min}$, postmortem interval $<48 \mathrm{~h}$ or frozen within $6 \mathrm{~h}$ following death) in the present institute were examined. The cases consisted of acute ischemic heart disease (AIHD, n=15) with/without apparent myocardial necrosis as a sign of infarction (acute myocardial infarction, $n=6$; ischemic heart disease, IHD, n=9), and arrhythmogenic right ventricular cardiomyopathy (ARVC/D, n=5), in addition to traffic accidents and high falls without any pre existing heart disease as control $(C$, total $n=6)$. BNP was investigated in all cases by the colloidal gold method, hematoxylin-eosin staining, immunohistochemistry (IHC) and the molecular pathological method. The IHC results demonstrated that a positive BNP immunostaining was detected in all groups; however, there was no difference between different causes of death. Pericardial N-terminal (NT)-proBNP concentration was significantly increased in deaths resulting from AIHD and ARVC/D compared with control group. The relative quantification of BNP mRNA demonstrated that relative expression levels of BNP mRNA were significantly increased in the left ventricle (LV) in the AIHD group, and in the RV of the ARVC/D group. The relative quantification difference and ratio of BNP mRNA between LV and RV demonstrated a significantly greater value in the AIHD group compared with control group. BNP mRNA in myocardium and NT-proBNP concentration in pericardial fluid were elevated in SCD patients, and left ventricular dysfunction predominated in AIHD patients, whereas right
\end{abstract}

Correspondence to: Dr Bao-Li Zhu, Department of Forensic Pathology, School of Forensic Medicine of China Medical University, No. 77, Puhe Road, Shenyang, Liaoning 110122, P.R. China

E-mail: zhu1127@hotmail.com

Key words: forensic pathology, sudden cardiac death, B-type natriuretic peptide, molecular pathology ventricular dysfunction predominated in ARVC/D patients. The results of the present study suggest the possible use of molecular pathology of BNP for the determination of terminal cardiac function in SCD and analysis of its fatal mechanism in forensic practice.

\section{Introduction}

Sudden death is defined as an unexpected natural death in apparently healthy individuals that takes place during the first hour after onset of symptoms. Almost $85 \%$ of all sudden death cases are of cardiac origin (sudden cardiac death, SCD), where it is a leading cause of death in Western countries, responsible for around 30-200 per 100,000 deaths every year (1). However, many SCDs lack typical morphological changes, which are called a negative autopsy, and are challenging for forensic pathologists. It is reported that $5-10 \%$ of these deaths are unexplained after a gross autopsy and $1-5 \%$ are negative after extensive autopsy (gross and microscopic examination, toxicological analysis and laboratory tests) (2,3). As a neurohormone, B-type natriuretic peptide (BNP) has been widely used as a sensitive biomarker for the diagnosis of heart failure in clinical practice (4-7). Previous studies also found BNP elevated in myocardium of SCD cases and demonstrated that BNP could reflect the terminal cardiac function as a postmortem biomarker in forensic practice (8-11). However, little is known about the different expression patterns of BNP in bilateral ventricles of different SCDs such as acute ischemic heart disease (AIHD), acute myocardial infarction (AMI) and arrhythmogenic right ventricular cardiomyopathy/dysplasia (ARVC/D).

The present study investigated the expression pattern of $\mathrm{BNP}$ as a biomarker of cardiac strain in different parts of the ventricle with special regard to AIHD, AMI and ARVC/D, using the molecular pathological method, hematoxylin and eosin (H\&E) staining, immunohistochemical (IHC) and the colloidal gold method.

\section{Materials and methods}

Materials. Twenty six forensic autopsy cases of sudden death (survival time $<30 \mathrm{~min}$, postmortem interval $<48 \mathrm{~h}$ or frozen within $6 \mathrm{~h}$ after death) in our institute were examined. The 
cases were made up of AIHD $(n=15)$ with/without apparent myocardial necrosis as a sign of infarction (AMI, $n=6$; IHD, $\mathrm{n}=9)$, and ARVC/D ( $=5)$, as well as traffic accidents and high falls without any pre existing heart disease as control $(\mathrm{C}$, total $\mathrm{n}=6$ ). There were 21 males and 5 females in these cases, aged between 14 and 70 years (median, 49). The causes of death were determined on the basis of a comprehensive medico-legal investigation, including autopsy examination and histological, toxicological and biochemical analyses. All cases with any pre existing pulmonary pathologies, poisoning, injuries or any other significant complications were excluded.

The heart diseases mentioned above were pathologically classified because of a lack of clinical history, and the main histopathological findings were as in previous studies: AMI, fresh localized myocardial damage (myocardial eosinophilic changes, typical ischemic coagulative necrosis with/without interstitial hemorrhage, or inflammatory infiltration); IHD, diffuse interstitial congestion, edema, patchy myocardial eosinophilic changes, in part accompanied by multiple hemorrhages and contraction bands, but without necrosis (12-14); ARVC/D, according to Protonotarios and Basso's diagnostic criteria, severely dilated right ventricle (RV) involving advanced myocardial atrophy with fibrofatty replacement in the right ventricular free wall, and not accompanied bylesion of conducting system and coronary arteries $(15,16)$. Details are shown in Table I.

In the present study, 1-2 $\mathrm{ml}$ of pericardial fluid were collected immediately from pericardial cavity during autopsy and stored at $-20^{\circ} \mathrm{C}$ to be used in the colloidal gold assay. The myocardial tissue specimens (about $100 \mathrm{mg}$ ) for mRNA measurements were collected from the same site in every case, including the anterior wall of the left ventricle (LV), the posterior wall of $\mathrm{LV}$ and the RV at autopsy. The myocardial tissue specimens were stored at $-80^{\circ} \mathrm{C}$ for RNA isolation. In addition, myocardial tissue was taken from the same site for IHC and H\&E staining.

All procedures performed in this study involving human participants were in accordance with the ethical standards of our institution's Ethical Committee and with the 1964 Helsinki declaration and its later amendments or comparable ethical standards.

\section{Materials and methods}

Measurement of NT-proBNP in pericardial fluid. The NT-proBNP concentration in the pericardial fluid was measured with a colloidal gold reagent kit (Getein Biotech, Inc., Nanjing, China) according to the manufacturer's instructions. The sensitive range of the kit is $100-35,000 \mathrm{pg} / \mathrm{ml}$. All the samples were diluted (x2) with normal saline. The concentration was considered as the minimum value $(200 \mathrm{pg} / \mathrm{ml})$ if it was lower than the sensitive range of the reagent kit. The clinical reference of NT-proBNP was $<300 \mathrm{pg} / \mathrm{ml}$ (17).

IHC and $H \& E$ staining. The myocardial tissue specimens were fixed in $4 \%$ paraformaldehyde in phosphate-buffered saline (PBS, $\mathrm{pH}$ 7.4) for $24 \mathrm{~h}$, and embedded in paraffin after being washed in water and dehydrated in a graded alcohol series and pellucidum in xylene. Afterwards, the paraffin block was cut into $5-\mu \mathrm{m}$ sections, which were then affixed to the slide with 3-aminopropyl-triethoxysilane (APES).
The sections were deparaffinized in xylene, rehydrated with a graded alcohol series, and then heated $10 \mathrm{~min}$ in $0.01 \mathrm{~mol} / \mathrm{l}$ sodium citrate buffer $(\mathrm{pH} 6.0)$ with a medical microwave oven for antigen retrieval. Subsequently, 3\% hydrogen peroxide was applied for quenching endogenous peroxidase activity. The sections were blocked with $10 \%$ non-immune goat serum to reduce non-specific binding. The sections were incubated with rabbit anti-BNP polyclonal antibody (dilution 1:500; AB125269; Abcam, Cambridge, UK) overnight at $4^{\circ} \mathrm{C}$. Immunostaining was performed using streptavidin-peroxidase and diaminobenzidine (DAB) according to the manufacturer's instructions (Zymed Life Technologies, Carlsbad, CA, USA). The sections were mounted with gummi after staining the nucleus with hematoxylin, being dehydrated in a gradedalcohol series and pellucidum in xylene. As controls for the immunostaining procedures, some sections were incubated with normal rabbit IgG or PBS in place of the primary antibody. $\mathrm{H} \& \mathrm{E}$ staining was conventionally conducted as our previous method (18).

Total RNA extraction and real-time RT-PCR. The myocardium specimen $(100 \mathrm{mg})$ was ground to a powder after being frozen in liquid nitrogen. Total RNA was extracted with RNAiso Plus (D9108; Takara Bio, Shiga, Japan), and immediately reverse-transcribed into cDNA with PrimeScript ${ }^{\mathrm{TM}}$ RT reagent kit (DRR037; Takara Bio). Aliquots of $10 \mu \mathrm{l}$ of reaction mixture contained $2 \mu 1$ of PrimeScript Buffer $(5 x)$, $0.5 \mu 1$ of PrimeScript RT Enzyme MixI, $0.5 \mu 1$ of OligodT Primer $(50 \mu \mathrm{M}), 0.5 \mu \mathrm{l}$ of Random 6 mers $(100 \mu \mathrm{M}), 4.5 \mu \mathrm{l}$ of $\mathrm{dH}_{2} \mathrm{O}$, and $2 \mu \mathrm{l}$ of total RNA (400 ng) with the GeneAmp ${ }^{\circledR}$ 9700 (Life Technologies, Grand Island, NY, USA) using the following conditions: $37^{\circ} \mathrm{C}$ for $15 \mathrm{~min}, 85^{\circ} \mathrm{C}$ for $5 \mathrm{~s}$ and $4^{\circ} \mathrm{C}$ for 5 min. Real-time PCR was performed with SYBR ${ }^{\circledR}$ Premix Ex Taq ${ }^{\mathrm{TM}}$ II (TliRNaseH Plus) (RR820A; Takara) in triplicate, usingthe 7500 Real-time PCR system (Life Technologies, CA, USA). Relative quantification was carried out by the comparative CT $(\Delta \Delta \mathrm{Cq})$ method to determine cDNA of BNP and the endogenous reference (GAPDH) simultaneously. Aliquots of $20 \mu \mathrm{l}$ of reaction mixture contained $6 \mu \mathrm{l}$ of $\mathrm{dH}_{2} \mathrm{O}, 10 \mu \mathrm{l}$ of $\mathrm{SYBR}^{\circledR}$ Premix Ex Taq ${ }^{\mathrm{TM}} \mathrm{II}(2 \mathrm{x}), 0.8 \mu \mathrm{l}$ of PCR forward primer $(10 \mu \mathrm{M}), 0.8 \mu \mathrm{l}$ of PCR reverse primer $(10 \mu \mathrm{M}), 0.4 \mu \mathrm{l}$ of ROX Reference Dye II (50x), and $2 \mu 1$ of cDNA. The amplification conditions were: $95^{\circ} \mathrm{C}$ for $30 \mathrm{~s}, 40$ cycles at $95^{\circ} \mathrm{C}$ for $5 \mathrm{~s}$, and $60^{\circ} \mathrm{C}$ for $34 \mathrm{~s}$. The primers of BNP and GAPDH designed by web-based IDT SciTools RealTime PCR software (19) are listed in Table II.

Statistical analysis. Comparisons between individual groups were performed using the nonparametric Mann-Whitney U test. Correlation analyses between pairs of parameters were performed using Spearman's rho test. The analysis was carried out using SPSS 19.0 (SPSS Inc., Chicago, USA). P<0.05 was considered to indicate a statistically significant difference.

\section{Results}

NT-proBNP concentration in pericardial fluid. According to the clinical reference, the pericardial NT-proBNP concentration was elevated in all groups of this study except the control group, and NT-proBNP was significantly higher in the 
Table I. Case profiles.

\begin{tabular}{|c|c|c|c|c|c|c|c|c|}
\hline \multirow{2}{*}{$\begin{array}{l}\text { Cause of } \\
\text { death }\end{array}$} & \multirow[b]{2}{*}{$\mathrm{n}$} & \multirow{2}{*}{$\begin{array}{c}\text { Male/ } \\
\text { female }\end{array}$} & \multicolumn{2}{|c|}{ Age (year) } & \multicolumn{2}{|c|}{ Heart weight (g) } & \multicolumn{2}{|c|}{ Combined lung weight $(\mathrm{g})$} \\
\hline & & & Range & Median & Range & Median & Range & Median \\
\hline \multicolumn{9}{|l|}{ AIHD } \\
\hline IHD & 9 & $7 / 2$ & $41-67$ & 54 & $320-650$ & 461 & 930-1585 & 1297 \\
\hline AMI & 6 & $5 / 1$ & $38-70$ & 55 & $400-728$ & 504 & $1000-1500$ & 1276 \\
\hline ARVC/D & 5 & $3 / 2$ & $30-54$ & 43 & $268-580$ & 454 & $855-1600$ & 1259 \\
\hline $\mathrm{C}$ & 6 & $6 / 0$ & $14-68$ & 42 & $260-380$ & 335 & $633-1390$ & 977 \\
\hline Total & 26 & $21 / 5$ & $14-70$ & 49 & $260-728$ & 441 & $633-1600$ & 1211 \\
\hline
\end{tabular}

$A I H D$ acute ischemic heart disease, $A M I$ acute myocardial infarction, $A R V C / D$ arrhythmogenic right ventricular cardiomyopathy/dysplasia, $C$ control.

Table II. Primer sequences used for reverse transcription-polymerase chain reaction.

\begin{tabular}{lll}
\hline Gene & Species & \multicolumn{1}{c}{ Primer } \\
\hline BNP & Homo sapiens & Forward: 5'-AAGATGGTGCAAGGGTCTG-3' \\
& & Reverse: 5'-TGTGGAATCAGAAGCAGGTG-3' \\
GAPDH & Homo sapiens & Forward: 5'-ACATCGCTCAGACACCATG-3' \\
& & Reverse: 5'-TGTAGTTGAGGTCAATGAAGGG-3'
\end{tabular}

Numbers (NM_) of the genes are National Center of Biotechnology Information (NCBI) accession numbers obtained from the NIH Database for human (H):BNP (H) NM_002521; GAPDH (H)NM_002046.

Table III. NT-proBNP concentration in pericardial fluid.

\begin{tabular}{|c|c|c|c|}
\hline \multirow{2}{*}{$\begin{array}{l}\text { Cause of } \\
\text { death }\end{array}$} & \multirow[b]{2}{*}{$\mathrm{n}$} & \multicolumn{2}{|c|}{$\begin{array}{l}\text { Pericardial BNP } \\
(\mathrm{pg} / \mathrm{ml})\end{array}$} \\
\hline & & Range & Median \\
\hline \multicolumn{4}{|l|}{ AIHD } \\
\hline $\mathrm{IHD}^{\mathrm{a}}$ & 9 & $200-10660$ & 2478 \\
\hline $\mathrm{AMI}^{\mathrm{a}}$ & 6 & $200-5165$ & 2174 \\
\hline $\mathrm{ARVC} / \mathrm{D}^{\mathrm{a}}$ & 5 & $200-3500$ & 1746 \\
\hline $\mathrm{C}$ & 6 & $200-254$ & 211 \\
\hline Total & 26 & $200-10660$ & 1810 \\
\hline
\end{tabular}

AIHD acute ischemic heart disease, AMI acute myocardial infarction, ARVC/D arrhythmogenic right ventricular cardiomyopathy/dysplasia, $\mathrm{C}$ control, a NT-proBNP was significantly higher in AIHD, AMI and $\mathrm{ARVC} / \mathrm{D}(\mathrm{P}<0.05)$.

ARVC/D, IHD and AMI groups compared with the control group. Details are shown in Table III.

$H \& E$ and IHC staining in the myocardium. H\&E (Fig. 1a-c) and IHC staining (Fig. 1d-f) were carried out in most cases of this study. In the sections with HE staining, some nonspecific changes such as edema, hemorrhage, myocardial wave and enhanced eosinophilic staining were present in the myocardium. The results showed that a positive BNP staining was detected in all groups, and that BNP in the myocardium of the endocardium expressed more than in the epicardium. However, there was no evident difference between the examined causes of death.

BNP and GAPDH mRNA expressions in the myocardium. $\mathrm{C}_{\mathrm{T}}$ values of BNP and GAPDH mRNA are shown in Table IV. With regard to the causes of death, relative quantification (RQ) of BNP mRNA to GAPDH mRNA in the anterior wall and posterior wall of the LV was significantly higher in the IHD and AMI group in contrast to the control group $(\mathrm{P}<0.05)$, and it was significantly higher in the posterior wall of the left and $\mathrm{RV}$ of ARVC/D compared with the control group $(\mathrm{P}<0.05)$. Details are shown in Fig. 2.

The RQ difference of BNP mRNA between LV (mean of anterior wall and posterior wall of LV) and RV showed a significantly higher value in the IHD and AMI groups compared with the control group $(\mathrm{P}<0.05)$, and also, the RQ ratio of $\mathrm{BNP}$ mRNA between LV and RV showed a significantly higher value in the IHD and AMI groups compared with the control group $(\mathrm{P}<0.05)$. Details are shown in Figs. 3 and 4.

Correlation of NT-proBNP and BNP mRNA with gender, age, heart weight and combined lung weight. To ascertain whether NT-proBNP and BNP mRNA were linked to gender, age, heart weight or combined lung weight, Spearman's rho test was applied. The results are as follows. 

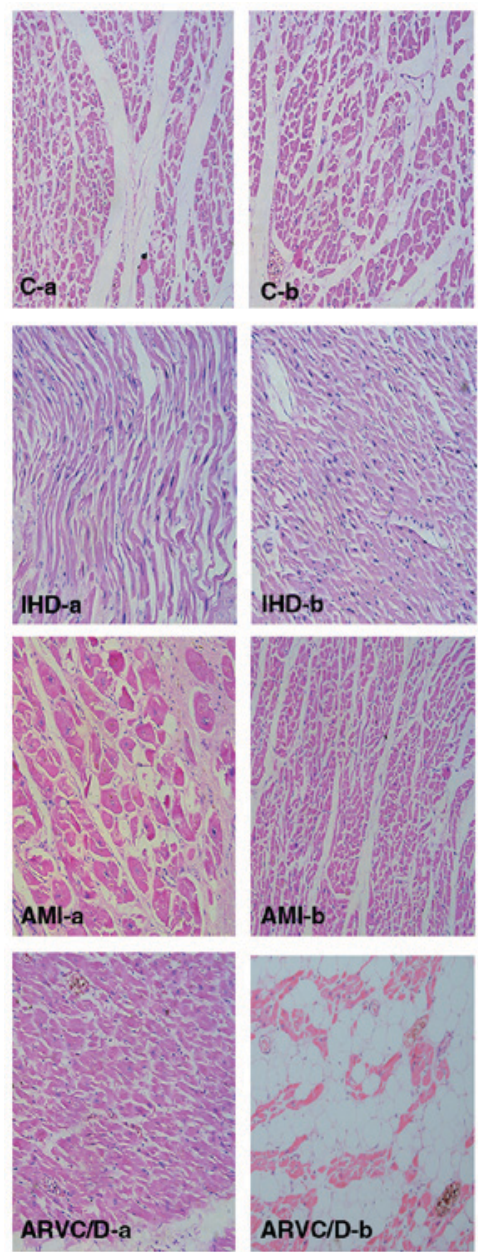
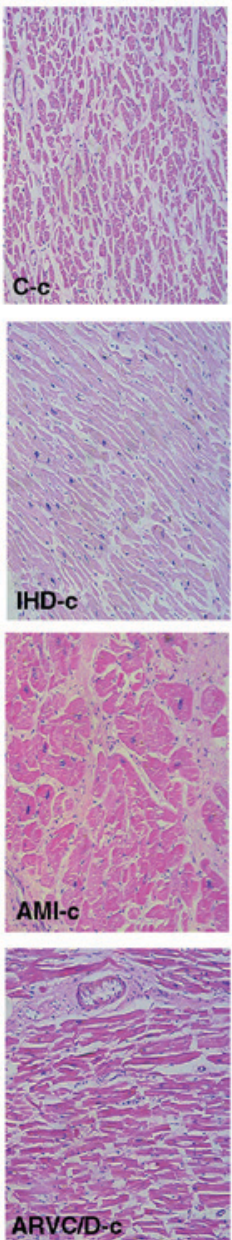
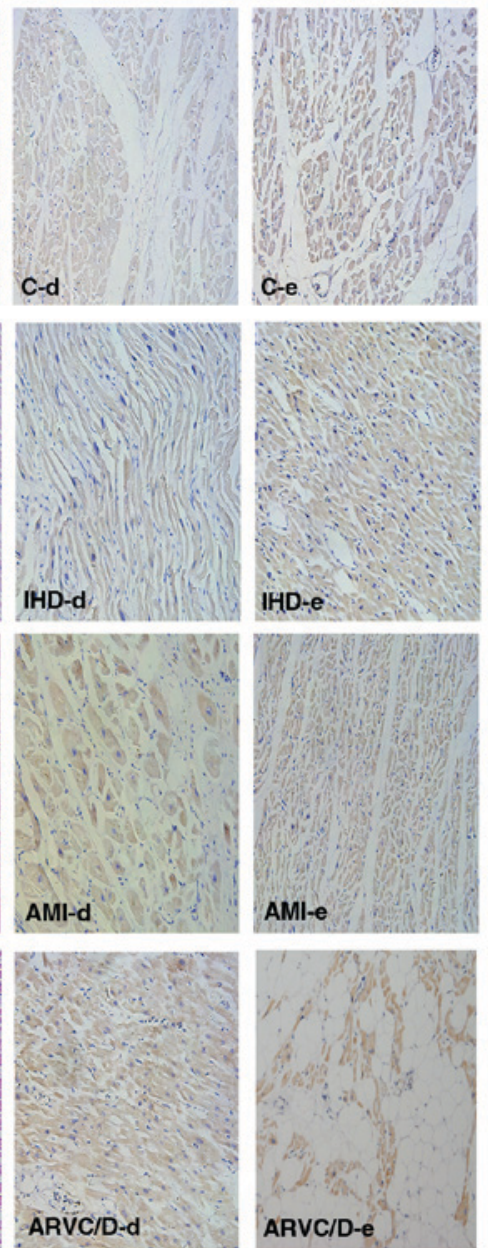
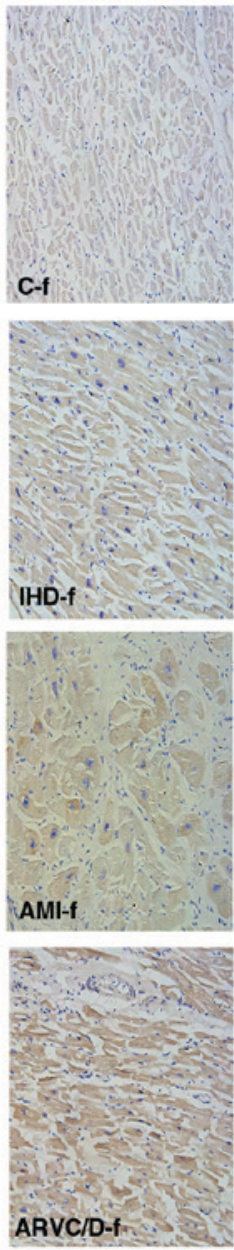

Figure 1. HE (a-c) and IHC (d-f) staining of BNP in the myocardium of different cases of death. C (control), a 48-year-old male died from high fall; IHD (ischemic heart disease), a 53-year-old male; AMI (acute myocardial infarction), a 62-year-old male; ARVC/D (arrhythmogenic right ventricular cardiomyopathy/dysplasia), a 38-year-old male. (a and d, left ventricle wall; b and e, right ventricle wall; c and f, ventricular septum). Other cases showed similar findings, and differences between the groups were not evident.

Table IV. CT value of BNP and GAPDH mRNA at different sites of myocardium in all cases.

$\mathrm{C}_{\mathrm{T}}$ value of mRNA

\begin{tabular}{lcc}
\cline { 2 - 3 } Site of myocardium & BNP (median) & GAPDH (median) \\
\hline $\begin{array}{l}\text { Anterior wall of } \\
\text { left ventricle }\end{array}$ & $18.5-32.4(26.3)$ & $17.7-26.0(21.9)$ \\
$\begin{array}{l}\text { Posterior wall of } \\
\text { left ventricle }\end{array}$ & $20.2-32.8(27.1)$ & $18.4-30.9(22.8)$ \\
\begin{tabular}{l} 
Right ventricle \\
\hline
\end{tabular} & $22.2-33.5(28.9)$ & $17.7-25.6(21.9)$ \\
\hline
\end{tabular}

Regardless of cause of death, no correlation existed between NT-proBNP and gender, age, combined lung weight or heart weight; but NT-proBNP was positively correlated slightly to BNP mRNA in the anterior wall posterior wall of $\mathrm{LV}(\mathrm{r}=0.505, \mathrm{P}=0.008 ; \mathrm{r}=0.504, \mathrm{P}=0.009)$. The correlation of heart weight with BNP mRNA of the anterior and posterior wall of LV was relatively small $(r=0.410, P=0.037 ; r=0.630$, $\mathrm{P}=0.001)$. The combined lung weight was positively correlated to heart weight $(\mathrm{r}=0.615, \mathrm{P}=0.001)$.

\section{Discussion}

BNP, a neurohormone originally isolated from porcine brain in 1988 by Sudoh et al (20), is a member of the natriuretic families, which consist of a number of structurally homologous but genetically distinct polypeptides. It is secreted mainly from the ventricles in patients with cardiac dysfunction (21). The expression and secretion of BNP increase significantly in bursts rather than stored in granules under pathological states due to stretching of the cardiomyocytes, cardiac volume overload, increased filling pressure of the heart, and ischemic injury, such as heart failure and myocardial infarction $(22,23)$. BNP is widely used as a marker for the diagnosis of heart failure in clinical practice (4-7). Sequence analysis reveals that pro-brain natriuretic peptide (pro-BNP) is split into two parts, the $\mathrm{N}$ - and $\mathrm{C}$-terminal parts, called N-terminal pro-BNP (NT-proBNP) and BNP, respectively (24). Zhu et al and Chen et al $(10,11,25,26)$ found that BNP could be used as a postmortem biomarker that could reflect the cardiac strain and terminal cardiac function after death, and it has been a routine laboratory item in some forensic institutions around the world. It has been demonstrated that BNP would elevated after SCD 


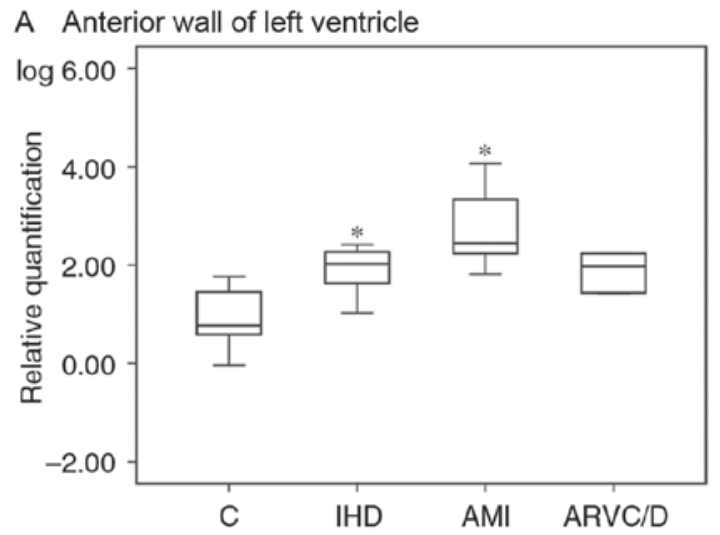

B Posterior wall of left ventricle

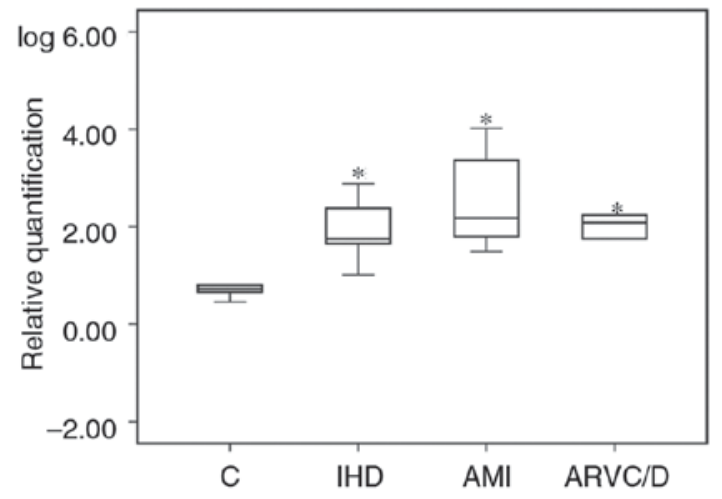

C Right ventricle

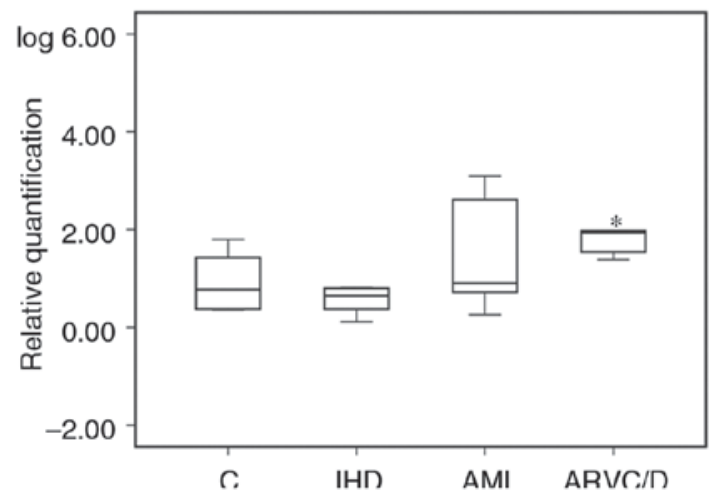

Figure 2. Relative quantification of BNP mRNA was performed at (A-C) different sites of myocardium with regard to the cause of death. $\left({ }^{*} \mathrm{P}<0.05\right.$ vs. control group). $C$ control, $I H D$ ischemic heart disease, $A M I$ acute myocardial infarction, $A R V C / D$ arrhythmogenic right ventricular cardiomyopathy/dysplasia.

caused by some diseases, while the expression pattern at different site of ventricle is not clear.

A previous study has reported that the frozen postmortem samples could affect the detection of BNP, so it was not a suitable method in forensic practice to detect BNP (27). However, there is originally an equal quantity of NT-proBNP and BNP. In addition, NT-proBNP is just as effective as BNP in the diagnosis of heart failure (28) and might be a more reliable biomarker, owing to its greater stability and longer half-life reported in the literature (29-32). Therefore, in the present study, we determined NT-proBNP instead of BNP in the pericardial fluid. The immunostaining of the myocardium showed positive staining in the bilateral ventricles and detected

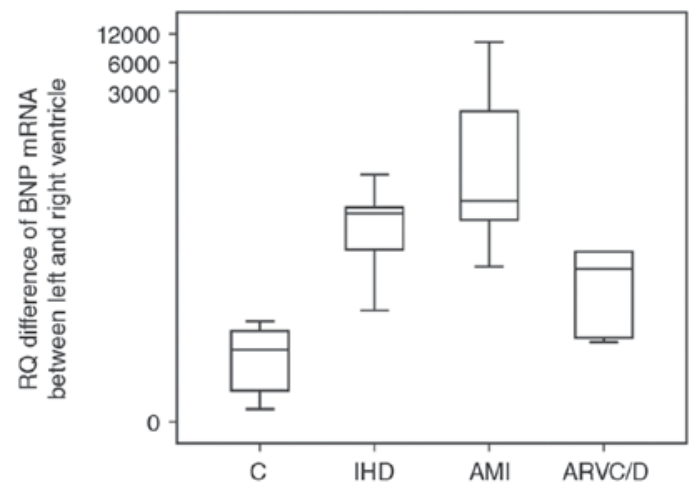

Figure 3. Difference in relative expression levels of BNP mRNA between LV (mean of anterior wall of LV and the posterior wall of LV) and RV. ( ${ }^{*} \mathrm{P}<0.05$ vs. control group).

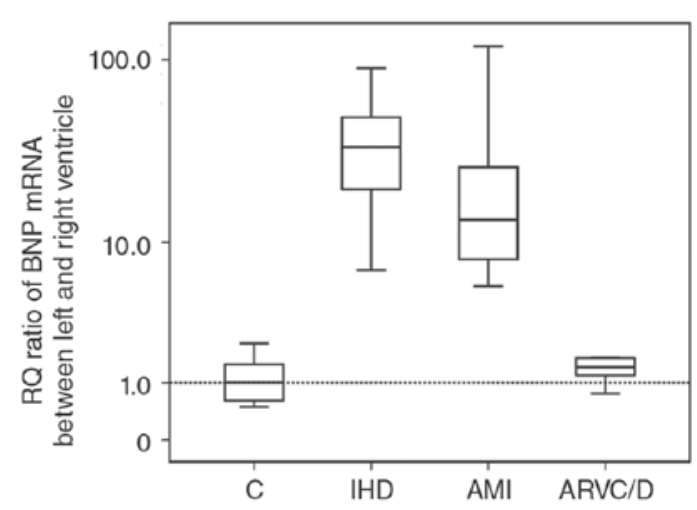

Figure 4. The relative quantification ratio of BNP mRNA between LV (mean of anterior wall of $\mathrm{LV}$ and the posterior wall of $\mathrm{LV})$ and $\mathrm{RV}$. ( ${ }^{*} \mathrm{P}<0.05$ vs. control group).

no difference between the examined causes of death. However, biochemical and molecular pathological analysis using the colloidal gold method and the RT-qPCR method showed a significant difference between causes of death as follows.

Both the IHD and AMI group showed higher BNP mRNA expressions in left ventricular walls in the present study in the contrast to control group, which indicated that acute cardiac dysfunction existed in IHD and AMI patients as shown in a previous study (33). The pericardial NT-proBNP concentration in the AIHD group was also higher than that in the control group, which suggested that the heart might express the BNP gene and secrete the protein rapidly responding to the acute increasing cardiac strain (33-37). Moreover, the pericardial NT-proBNP concentration in the AMI group was a little lower than the IHD group. Zhu et al (13) found that cardiac troponin $\mathrm{T}$ (cTnT), which is the biomarker of myocardial necrosis, had a negative correlation with BNP. Thus, the lower NT-proBNP concentration in pericardial fluid in AMI may be due to the necrotic myocardium's failure to express and secrete BNP.

Several experiments have demonstrated that myocardial ischemia could lead to arrhythmias (38-40). In some cases in the present study examining bilateral ventricular BNP mRNA, there was a difference in BNP mRNA between LV and RV, and pericardial NT-proBNP concentration in the IHD 
group showed a similar expression profile as in the ARVC/D group, suggesting the possible occurrence of lethal arrhythmias caused by changes in myocardiocyte rhythm in the IHD patients during myocardial ischemia.

In the ARVC/D group of the present study, BNP mRNA showed higher expressions in the posterior wall of LV and RV compared with control group, and as well, the NT-proBNP concentration in the pericardial fluid was also elevated, as reported in a previous study (25). In ARVC/D, $\mathrm{RV}$ disease predominates, but more than half of the hearts studied at postmortem disclosed LV involvement, usually limited to the subepicardium of the postero-lateral free wall (41). The involvement of the ventricular septum is rare, probably because it is not a subepicardial structure (42). In our study, consequently, we determined BNP mRNA of $\mathrm{RV}$, the anterior wall and posterior wall of $\mathrm{LV}$, respectively. Fibrofatty replacement of the myocardium was observed in the RV but not LV, but BNP mRNA was elevated in bilateral ventricles. The result indicated that the left ventricular wall pressure would increase and the function of LV would be affected during the occurrence of ARVC/D, even if there were no left ventricular structural changes. In addition, although BNP mRNA was elevated in bilateral ventricles of ARVC/D patients, the relative quantification difference of BNP mRNA between LV and RV was much lower than in the IHD and AMI groups, which indicated a similar cardiac dysfunction severity in the LV and RV of ARVC/D patients. The AIHD group, on the contrary, showed a significantly higher relative quantification difference and ratio of BNP mRNA between $\mathrm{LV}$ and RV, which indicated that unilateral ventricular dysfunction predominated in the AIHD patients. The unilateral ventricular dysfunction may be caused by the dominating coronary lesion in the AIHD patients. This might be the difference between the AIHD group and the ARVC/D group. In addition, NT-proBNP and BNP mRNA was not correlated with gender, age, heart weight and combined lung weight in the ARVC/D group, which indicated that BNP was an independent diagnostic marker.

In conclusion, the present molecular pathological study investigated the different expression of BNP between LV and RV in SCD. The results showed that both BNP mRNA in myocardium and NT-proBNP concentration in pericardial fluid was elevated in SCD patients, and that left ventricular dysfunction predominated in AIHD patients while right ventricular dysfunction predominated in ARVC/D patients. The results of the present study suggest the possible use of the molecular pathology of BNP for the determination of the terminal cardiac function in SCD and analysis of its death mechanism in forensic practice.

\section{Acknowledgements}

This study was funded by the National Natural Science Foundation of China (grant no. 81273343).

\section{References}

1. Campuzano O, Allegue C, Partemi S, Iglesias A, Oliva A and Brugada R: Negative autopsy and sudden cardiac death. Int J Legal Med 128: 599-606, 2014.
2. Lawler W: The negative coroner's necropsy: A personal approach and consideration of difficulties. J Clin Pathol 43: 977-980, 1990.

3. Mendis S, Thygesen K, Kuulasmaa K, Giampaoli S, Mähönen M, Ngu Blackett K and Lisheng L; Writing group on behalf of the participating experts of the WHO consultation for revision of WHO definition of myocardial infarction: World Health Organization definition of myocardial infarction: 2008-09 revision. Int J Epidemiol 40: 139-146, 2011.

4. Troughton R, Michael Felker G and Januzzi JL Jr: Natriuretic peptide-guided heart failure management. Eur Heart J 35: 16-24, 2014.

5. Kossaify A, Garcia A, Succar S, Ibrahim A, Moussallem N, Kossaify $M$ and Grollier G; STAR-P Consortium: Perspectives on the value of biomarkers in acute cardiac care and implications for strategic management. Biomark Insights 8: 115-126, 2013.

6. MacGowan GA, Neely D, Peaston R, Wrightson N and Parry G: Evaluation of NT-proBNP to predict outcomes in advanced heart failure. Int J Clin Pract 64: 892-899, 2010.

7. Maries L and Manitiu I: Diagnostic and prognostic values of B-type natriuretic peptides (BNP) and N-terminal fragment brain natriuretic peptides (NT-pro-BNP). Cardiovase J Afr 24: 286-289, 2013.

8. Sabatasso S, Vaucher P, Augsburger M, Donzé N, Mangin P and Michaud K: Sensitivity and specificity of NT-proBNP to detect heart failure at post mortem examination. Int J Legal Med 125: 849-856, 2011.

9. Palmiere C and Mangin P: Postmortem biochemical investigations in hypothermia fatalities. Int J Legal Med 127: 267-276, 2013.

10. Zhu BL, Ishikawa T, Michiue T, Li DR, Zhao D, Tanaka S, Kamikodai Y, Tsuda K, Okazaki S and Maeda H: Postmortem pericardial natriuretic peptides as markers of cardiac function in medico-legal autopsies. Int J Legal Med 121: 28-35, 2007.

11. Chen JH, Michiue T, Ishikawa T and Maeda H: Molecular pathology of natriuretic peptides in the myocardium with special regard to fatal intoxication, hypothermia, and hyperthermia. Int J Legal Med 126: 747-756, 2012.

12. Zhu BL, Tanaka S, Ishikawa T, Zhao D, Li DR, Michiue T, Quan L and Maeda H: Forensic pathological investigation of myocardial hypoxia-inducible factor-1 alpha, erythropoietin and vascular endothelial growth factor in cardiac death. Leg Med (Tokyo) 10: 11-19, 2008

13. Zhu BL, Ishikawa T, Michiue T, Li DR, Zhao D, Oritani S, Kamikodai Y, Tsuda K, Okazaki S and Maeda H: Postmortem cardiac troponin T levels in the blood and pericardial fluid. Part 1. Analysis with special regard to traumatic causes of death. Leg Med (Tokyo) 8: 86-93, 2006.

14. Thygesen K, Alpert JS and White HD; Joint ESC/ACCF/AHA/WHF Task Force for the Redefinition of Myocardial Infarction: Universal definition of myocardial infarction. Eur Heart J 28: 2525-2538, 2007.

15. Protonotarios N, Anastasakis A, Antoniades L, Chlouverakis G, Syrris P, Basso C, Asimaki A, Theopistou A, Stefanadis C, Thiene G, et al: Arrhythmogenic right ventricular cardiomyopathy/dysplasia on the basis of the revised diagnostic criteria in affected families with desmosomal mutations. Eur Heart J 32: 1097-1104, 2011.

16. Basso C, Ronco F, Marcus F, Abudureheman A, Rizzo S, Frigo AC, Bauce B, Maddalena F, Nava A, Corrado D, et al: Quantitative assessment of endomyocardial biopsy in arrhythmogenic right ventricular cardiomyopathy/dysplasia: An in vitro validation of diagnostic criteria. Eur Heart J 29: 2760-2771, 2008.

17. Madamanchi C, Alhosaini H, Sumida A and Runge MS: Obesity and natriuretic peptides, BNP and NT-proBNP: Mechanisms and diagnostic implications for heart failure. Int J Cardiol 176: 611-617, 2014.

18. Cao ZP, Zhang Y, Mi L, Luo XY, Tian MH and Zhu BL: The expression of B-type natriuretic peptide after $\mathrm{CaCl} 2$-induced arrhythmias in rats. Am J Forensic Med Pathol 37: 133-140, 2016.

19. http: //www.idtdna.com/scitools/Applications/RealTimePCR/. In.

20. Sudoh T, Kangawa K, Minamino N and Matsuo H: A new natriuretic peptide in porcine brain. Nature 332: 78-81, 1988.

21. Daniels LB and Maisel AS: Natriuretic peptides. J Am Coll Cardiol 50: 2357-2368, 2007.

22. Semenov AG and Seferian KR: Biochemistry of the human B-type natriuretic peptide precursor and molecular aspects of its processing. Clin Chim Acta 412: 850-860, 2011. 
23. Yasue H, Yoshimura M, Sumida H, Kikuta K, Kugiyama K, Jougasaki M, Ogawa H, Okumura K, Mukoyama M and Nakao K: Localization and mechanism of secretion of B-type natriuretic peptide in comparison with those of A-type natriuretic peptide in normal subjects and patients with heart failure. Circulation 90: 195-203, 1994

24. Snipsøyr MG, Ludvigsen M, Petersen E, Wiggers H and Honoré B: A systematic review of biomarkers in the diagnosis of infective endocarditis. Int J Cardiol 202: 564-570, 2016.

25. Chen JH, Michiue T, Ishikawa T and Maeda H: Pathophysiology of sudden cardiac death as demonstrated by molecular pathology of natriuretic peptides in the myocardium. Forensic Sci Int 223 342-348, 2012.

26. Chen JH, Michiue T, Ishikawa T and Maeda H: Difference in molecular pathology of natriuretic peptides in the myocardium between acute asphyxial and cardiac deaths. Leg Med (Tokyo) 14: 177-182, 2012.

27. Michaud K, Augsburger M, Donzé N, Sabatasso S, Faouzi M, Bollmann M and Mangin P: Evaluation of postmortem measurement of NT-proBNP as a marker for cardiac function. Int J Legal Med 122: 415-420, 2008.

28. Mueller T, Gegenhuber A, Poelz W and Haltmayer M: Diagnostic accuracy of B type natriuretic peptide and amino terminal proBNP in the emergency diagnosis of heart failure. Heart 91: 606-612, 2005

29. Pfister R, Scholz M, Wielckens K, Erdmann E and Schneider CA Use of NT-proBNP in routine testing and comparison to BNP. Eur J Heart Fail 6: 289-293, 2004.

30. Gill D, Seidler T, Troughton RW, Yandle TG, Frampton CM, Richards M, Lainchbury JG and Nicholls G: Vigorous response in plasma N-terminal pro-brain natriuretic peptide (NT-BNP) to acute myocardial infarction. Clin Sci (Lond) 106: 135-139, 2004.

31. Kragelund C, Grønning B, Køber L, Hildebrandt P and Steffensen R: N-terminal pro-B-type natriuretic peptide and long-term mortality in stable coronary heart disease. N Engl J Med 352: 666-675, 2005.

32. Nowatzke WL and Cole TG: Stability of N-terminal pro-brain natriuretic peptide after storage frozen for one year and after multiple freeze-thaw cycles. Clin Chem 49: 1560-1562, 2003.

33. Hama N, Itoh H, Shirakami G, Nakagawa O, Suga S, Ogawa Y, Masuda I, Nakanishi K, Yoshimasa T, Hashimoto Y, et al: Rapid ventricular induction of brain natriuretic peptide gene expression in experimental acute myocardial infarction. Circulation 92 $1558-1564,1995$.
34. Nakagawa O, Ogawa Y, Itoh H, Suga S, Komatsu Y, Kishimoto I, Nishino K, Yoshimasa T and Nakao K: Rapid transcriptional activation and early mRNA turnover of brain natriuretic peptide in cardiocyte hypertrophy. Evidence for brain natriuretic peptide as an 'emergency' cardiac hormone against ventricular overload. J Clin Invest 96: 1280-1287, 1995.

35. Nunez J, Nuñez E, Robles R, Bodí V, Sanchis J, Carratalá A, Aparici $\mathrm{M}$ and Llàcer $\mathrm{A}$ : Prognostic value of brain natriuretic peptide in acute heart failure: Mortality and hospital readmission. Rev Esp Cardiol 61: 1332-1337, 2008.

36. Omland T and Hagve TA: Natriuretic peptides: Physiologic and analytic considerations. Heart Fail Clin 5: 471-487, 2009.

37. Mukoyama M, Nakao K, Obata K, Jougasaki M, Yoshimura M, Morita E, Hosoda K, Suga S, Ogawa Y, Yasue H, et al: Augmented secretion of brain natriuretic peptide in acute myocardial infarction. Biochem Biophys Res Commun 180: 431-436, 1991.

38. Baartscheer A, Schumacher CA, Wekker V, Verkerk AO, Veldkamp MW, van Oort RJ, Elzenaar I, Ottenhoff R, van Roomen C, Aerts H and Coronel R: Dyscholesterolemia protects against ischemia-induced ventricular arrhythmias. Circ Arrhythm Electrophysiol 8: 1481-1490, 2015.

39. Fischer TH, Eiringhaus J, Dybkova N, Förster A, Herting J, Kleinwächter A,Ljubojevic S, Schmitto JD, Streckfuß-Bömeke K,

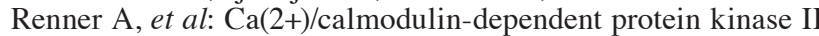
equally induces sarcoplasmic reticulum $\mathrm{Ca}(2+)$ leak in human ischaemic and dilated cardiomyopathy. Eur J Heart Fail 16: 1292-1300, 2014

40. Fischer TH, Herting J, Tirilomis T, Renner A, Neef S, Toischer K, Ellenberger D, Förster A, Schmitto JD, Gummert J, et al: $\mathrm{Ca} 2+/$ calmodulin-dependent protein kinase II and protein kinase A differentially regulate sarcoplasmic reticulum $\mathrm{Ca} 2+$ leak in human cardiac pathology. Circulation 128: 970-981, 2013.

41. Corrado D, Basso C, Thiene G, McKenna WJ, Davies MJ, Fontaliran F, Nava A, Silvestri F, Blomstrom-Lundqvist C, Wlodarska EK, et al: Spectrum of clinicopathologic manifestations of arrhythmogenic right ventricular cardiomyopathy/dysplasia: A multicenter study. J Am Coll Cardiol 30: 1512-1520, 1997.

42. Thiene G, Angelini A, Basso C, Calabrese F and Valente M: Novel heart diseases requiring transplantation. Adv Clin Path 2: 65-73, 1998. 